\title{
The Effect of Team-Based Learning Coupled with Merrill's First Principles of Instruction on the Achievement of Learning Objectives in Nursing Students
}

\author{
Mehdi Badali, ${ }^{1,}$ Sadaf Alizadeh Derakhshi, ${ }^{2}$ Parisa Bagheri, ${ }^{3}$ and Mohammad Reza Ansari ${ }^{2}$ \\ ${ }^{1}$ Department of Education, Tarbiat Modarres University, Tehran, IR Iran \\ ${ }^{2}$ Allameh Tabatabaei University, Tehran, IR Iran \\ ${ }^{3}$ Kharazmi University, Tehran, IR Iran \\ "Corresponding author: Mehdi Badali, PhD Student in Educational Technology, Department of Education, Tarbiat Modarres University, Tehran, IR Iran. E-mail: \\ badali.tech@gmail.com
}

Received 2016 October 30; Accepted 2016 December 20.

\begin{abstract}
Introduction: Team-based learning is one of the methods concerned in medical education. Teaching and learning have some principles known as Merrill's first principles that are a basis for effective education. This study examined the effect of using team-based learning combined with Merrill's Principles on achieving learning objectives in nursing students.

Methods: This was a semi-experimental, applied research that used pretest-posttest design with a control group. The statistical population included all undergraduate students of Ardebil University of Medical Sciences, Meshkin Shahr campus, in 2015-2016. The sample group comprised a class of nursing students selected by convenience sampling method $(\mathrm{n}=47)$. The subjects were divided into two groups of control $(n=23)$ and test $(n=24)$ using simple random allocation. A pretest was given to both groups prior to the implementation of the training. Then, the intended plan was executed for 5 weeks and at the end, a posttest was administered. The data were analyzed by applying covariance analysis test using SPSS version 20 .

Results: The results showed that the learning objectives scores in the test group increased from 2.68 and 1.31 to 17.83 and 12.16 for remembrance and application levels, respectively, while the increments were not significant in the control group. In other words, there was a significant difference in the achievement of learning objectives between the test and control groups $(\mathrm{P}<0.001)$, implying that the test group had better learning.

Conclusions: By using team-based learning combined with Merrill's First Principles, we can improve learning objectives achievements.
\end{abstract}

Keywords: Team-Based Learning, Learning Objectives, Merrill's First Principles of Instruction, Nursing, Students

\section{Introduction}

Meaningful learning and desirable remembrance are achieved as a result of effective training (1). Effective training is necessary for improving knowledge, ability, and attitude in order to increase learning in professional fields such as medical sciences and paramedics. Nowadays, we can observe the increasing expansion of teaching medical sciences to medical students (2). The selection of teaching and learning methods is one of the most important subjects in medical sciences. At present, lecture is the dominant tool of education in medicine faculties (3). Lecture is a kind of traditional tool of instruction (4), which is rooted in 500 B.C. Despite being old, this technique is used still by many teachers to learn students through information transferring. Lecture is recognized as a method that prevents students from good comprehension and understanding of the sciences $(5,6)$.

Lecture is one of the most common methods of knowl- edge transferring at different levels. Although in this method a bunch of scientific content is transferred from teacher to students, there could not usually be made deep meaningful learning. This method lacks effectiveness in training of medical students to perform their professional duties in future (7). Information transferring from teacher to students in the lecture method makes the students passive. They are remained bored, their creativity is not cultivated, and they are merely information receivers. In conclusion, the lecture method is said to be an ineffective method (8).

Contrary to the lecture method, that prevents students from learning, active learning improves learning skills of learners. Researches show that active learning can improve the perception and understanding of the learners because it facilitates learning process $(6,9)$. In active learning, the learners have more opportunity to establish an interactive relationship with the courses, and they are encouraged to generate knowledge and apply it in their life 
(4). Teachers are more learning facilitator in active learning instead of dictating knowledge to their students. The idea of creating meaningful learning is now emphasized by educational scientists in all courses, especially the experimental sciences (10).

In order to do active learning, various approaches are considered including "team-based learning" (TBL) and theory of "Merrill's first principles of instruction". Team-based learning was created in teaching medical and paramedical training courses by revision of curriculum in all medical schools, including schools in Tehran University of Medical Sciences. The revisions have considered the reform of teaching methods and the use of student-oriented methods (11).

Dr. Larry K Michael invented team-based learning method in 1998 with the aim of improving the quality of students' learning through problem solving skills, ensuring the presence of students in readiness, and forming active learning and energetic class (12). In spite of creating an active and cooperative learning environment, this method does not require a special work place, small group of learners, or increased number of instructors so that it is applicable by only one instructor in a crowded class (above 100 students). Team-based learning focuses on individual and team responsiveness, group engagement and interaction, and participation motivation (11).

As mentioned earlier, in addition to team-based learning, another method and educational theory causing activation of students' learning is the theory of Merrill's First principles of instruction. Merrill (13) criticized the lecture method declaring that "Mere transmission of information is NOT learning and teaching". He believes that instruction has some principles called "first principles of instruction" that underpin the effective training. This theory was called Merrill's First principles of instruction. He reviewed different patterns and experiences of educational methods to create the above principles.

Merrill believes that his first principles of education are one of the patterns used for designing training and educational environments (14). These principles were expressed in an article in 2007 by Merrill himself and supported by other authors and researchers (15). The first principles of instruction contain five important educational principles making the teaching as meaningful for learners and they get more active in learning procedure. These five basic principles of education are as follows:

1) Principle of problem-orientated or task-based

2) Principle of activation

3) Principle of demonstration

4) Principle of application

5) Principle of integration

Merrill has raised the theory of "First principles of in- struction" in his most recent researches. Merrill's educational theory of first principles of instruction is quite different from Merrill's educational pattern design and the doctrine of components demonstration (that is tested and experimented repeatedly locally or in abroad). Badali (10) indicated in a study about Merrill's first principles of instruction that the students who became the subject of Merrill's principles in teaching were more successful in learning and remembrance compared to students learned through traditional methods.

One of the researches regarding Merrill's first principles of instruction was conducted by Gardner (4) using experimental method. In the study, the researcher came to the conclusion that active teaching method (by using five basic principles) has positive impact on learning (in knowledge and understanding levels) and problem solving ability of students in a biology classroom and it can improve students' problem solving and learning skills. Archibald (16), in another study, used Merrill's first principles of instruction integrated with social annotation and team-based learning. The results showed that the combination had positive impacts on comprehension, metacognitive skills, and critical thinking of students.

In a study conducted by Jafari (17) on undergraduate students of rehabilitation entitled "Learning level of nosology course in rehabilitation students through lecture method and team-based learning (TBL)", it was found that students have more success through team-based learning method compared to the lecture method. The results of this study can help students, teachers, and educational authorities to rethink about the effect of proper selection of educational methods on knowledge transfer and achieving the determined educational objectives. All the mentioned studies have examined the Merrill's First principles of instruction and team-based learning separately. However, team-based learning is able to be integrated with Merrill's five principles of instruction to improve teaching and learning.

As mentioned above, active learning can improve perception and understanding of the learners because it facilitates learning process $(6,9)$. Active learning takes place when the learners have more opportunities to establish interacted relationship with the subject of courses and be encouraged to generate knowledge and apply it in their life. Merrill's first principles of instruction theory and teambased learning make students active in learning; therefore, it seems that using these two methods as a combination can make learning as meaningful. Thus, the main question of this study is whether Merrill's first principles of instruction and team-based learning as a combination can be effective in achieving educational objectives in terms of remembrance and application in nursing students. Thus, the 
following hypotheses are proposed:

1) Merrill's first principles of instruction and teambased learning, as a combination, are effective in the achievement of remembrance objectives among nursing students.

2) Merrill's first principles of instruction and teambased learning, as a combination, are effective in the achievement of application objectives among nursing students.

\section{Methods}

A semi-experimental study was conducted using pretest-posttest design with a control group. The statistical population included all undergraduate students of Ardabil University of Medical Sciences, Meshkin Shahr campus, in the first semester of educational year 2015 2016. The sample included a class of nursing students selected through convenience sampling method. The reason for using this sampling method was the availability and easiness of the implementation in the above-mentioned class and university. All the students in the selected class $(n=47)$ were divided into 2 groups of 23 and 24 persons named control and test groups, respectively, by simple random allocation. To this end, the students were given numbers from 1 to 47 randomly; then, 1 - 23 formed the control group and 24 - 47 the test group.

The criteria for inclusion were: 1) being undergraduate student in nursing, $\mathrm{b}$ ) having taken the course of nutrition and nutrition therapy and, 3 ) having enough motivation to participate in the research. Students who missed more than 2 sessions were excluded. Ethical considerations were met in this study given that the score of each student in the tests was reported to him/herself confidentially and the obtained scores had no effect on their semester final scores. The required coordination was made with the University for the implementation of the study.

The nutrition and nutrition therapy professor was asked to apply Merrill's first principles of instruction and team-based learning methods. First, a pretest was given to both control and test groups regarding learning objectives in the levels of remembrance and application. The content validity of this tool in pretest was approved by applying the comments of nursing teachers of the University and its reliability was calculated as 0.37 and 0.81 , respectively, using Cronbach's alpha. Then, the selected lessons were provided for both groups.

Training was provided for the control group through the traditional education method, while for the test group, the lessons were designed based on Merrill's first principles of instruction and team-based learning methods (for more information please refer to the example in the attachment). In order to observe the ethical principles, the same intervention was implemented on the other group after the completion of the research. In addition, a testimonial was designed and distributed to the samples to explain the goal of the research and emphasize the confidentiality of the results.

A same researcher, who had made the tests, assessed the learning objectives in the levels of remembrance and application. On questions related to the remembrance level, it was necessary for students to memorize information. This section consisted of 20 questions scored from 0 to 1 . In questions related to the application level, it was necessary for the individual to apply what he/she has learnt. This section contained 10 questions each scored $0-2$. To assess the validity of the test, the researcher concerned the experts and professors' recommendations and used the bidirectional table of objectives-content. The reliability of the test was calculated using the correlation between the two halves which gave the values of 0.78 and 0.75 , respectively.

At the end of the training (which lasted 5 weeks), the posttest was administered to both groups in the levels of remembrance and application. The validity of the tool in posttest was approved as for the pretest and the reliability was also confirmed using Cronbach's alpha by obtaining the coefficients of 0.75 and 0.80 , respectively. Finally, the hypotheses of the study were evaluated considering the scores of pretest and posttest in the levels of remembrance and application. To perform statistical calculations, SPSS version 20 was used and the data were analyzed using Covariance analysis.

\section{Results}

47 students participated in this study (16 boys and 31 girls). The mean age of the students was 21.7 with a standard deviation of 11 months. A summary of the obtained results is presented in Table 1.

Univariate analysis of covariance (ANCOVA) was employed to examine the hypotheses of the study. It was because the researchers were to control the effects of previous preparation in the students; therefore, they used pretest as control variable. Before using ANCOVA, we must review some important assumptions about the mentioned statistical test, because the lack of considering those assumptions may cause a bias in the results. To check the presumptions of ANCOVA, Kolmogorov-Smirnov test and Levene's test were used and the obtained results are presented in Tables 2 and 3, respectively.

According to Tables 2-4, it can be inferred that all three assumptions of covariance analysis are observed. That is, 
Table 1. Description of Pretest and Posttest Scores in Remembrance and Application Levels of Learning Based on the Groups

\begin{tabular}{l|c|c|c}
\hline Descriptions of groups & Group & Number & Mean \pm SD \\
\hline \multirow{2}{*}{ Remembrance pretest scores } & Control & 23 & $2.40 \pm 0.82$ \\
\cline { 2 - 4 } & Test & 24 & $2.68 \pm 0.74$ \\
\hline \multirow{2}{*}{ Application pretest scores } & Control & 23 & $1.40 \pm 0.42$ \\
\cline { 2 - 4 } & Test & 24 & $1.31 \pm 0.37$ \\
\hline \multirow{2}{*}{ Remembrance posttest scores } & Control & 23 & $15.12 \pm 2.03$ \\
\cline { 2 - 4 } & Test & 24 & $17.83 \pm 1.64$ \\
\hline \multirow{2}{*}{ Application posttest scores } & Control & 23 & $13.04 \pm 2.24$ \\
\cline { 2 - 4 } & Test & 24 & $16.12 \pm 2.07$ \\
\hline
\end{tabular}

the use of ANCOVA was tenable to analyze the data of this research.

Covariance analysis test results regarding posttest scores of remembrance learning level are shown in Table 5. As can be seen, the total mean square of independent variable is 83.12 , leading to the significance level of 0.001 , which means the effect is significant at the level of $1 \%$. In other words, even after controlling the pretest effects, the difference between the two groups of control and test is significant with confidence of $99 \%$. With respect to the mean scores of the test and control groups in the posttest, we can conclude that using Merrill's first principles of instruction and team-based learning methods, as a combination, is more effective than traditional education method in the achievement of remembrance objectives.

Covariance analysis test results regarding posttest scores of application learning level are shown in Table 6. As observed, the total mean square of independent variable is 104.2, leading to the significance level of 0.001, which indicates a significant effect at the level of $1 \%$. In other words, even after controlling the pretest effects, the difference between the two groups of control and test is significant with confidence of $99 \%$. With respect to the mean scores of the test and control groups in the post-test, we can conclude that using Merrill's first principles of instruction and team-based learning methods, as a combination, is more effective than traditional education method on application level of learning.

\section{Discussion and Conclusion}

The overall goal of this study was to determine the effectiveness of instructional design based on Merrill's first principles of learning and team-based learning as a combination in remembrance and application levels of learning in nursing students. To this end, the extent of learning in the remembrance and application levels (based on Merrill's objectives classification) was compared between the students educated through the combination of Merrill's first principles of instruction and team-based learning (test group) and students educated through traditional method (control group).

The obtained results indicated that there was a significant difference in both learning levels of remembrance and application between the test and control groups. The learning in both levels was better in the students educated with the combined method of learning compared to the students educated with traditional method. Therefore, the hypothesis of the research was confirmed. The results obtained in this study is in agreement with those of studies conducted by Zare'I Zavaraki et al. (18), Latifi (1), Gardner (4), Archibald (16), Thompson Ins. (19), and Nordhoff(20).

It seems the main reason for the improvement of learning in the two levels of remembrance and application in students is the use of training based on the first principles underpinning the effective learning (i.e. Merrill's first principles of instruction) in combination with team-based learning, which is one of the approaches to make the learning more effective. Merrill's first principles of instruction include five principles of problem-oriented or task-based, activation, demonstration, application, and integration principles.

The principle of problem-oriented is one of the important principles of this theory. When this principle is considered, the students are engaged in problems or tasks and hence, the effective learning is achieved. Moreover, the concepts take place in learners as meaningful because of their engagement in problem or task. Therefore, the remembrance of the concepts is facilitated which, in turn, makes students be able to apply the acquired knowledge whenever they need. Gardner (4) in a study also indicated that the use of Merrill's first principles of education has positive effects on problem solving and learning in biology students.

According to this theory, after presenting the problem, the activation of students begins from the point the learner is (21). In some cases, it has been observed that the educator starts the education regardless of the previous or existing knowledge of the learner, while it should be noted that if a learner cannot relate the new topic to existing knowledge in his/her mind, learning does not take place. Therefore, it can be said that every educational plan that successfully affects the activation of previous knowledge of learners will improve learning and remembrance. Nordhoff's study (20) showed that activation of previous knowledge of students is of great importance in the success of the Merrill's pattern and can let us achieve more than we get from the use of lectures, textbook, exercises, 
Table 2. Kolmogorov-Smirnov test to Check Normality of Data Distribution in the Control and Test Groups

\begin{tabular}{|c|c|c|c|c|c|}
\hline \multirow[t]{2}{*}{ Group } & \multirow[t]{2}{*}{ Tests } & \multicolumn{2}{|c|}{ Application } & \multicolumn{2}{|c|}{ Remembrance } \\
\hline & & Pretest & Posttest & Pretest & Posttest \\
\hline \multirow{2}{*}{ Control group } & $Z$ test & 0.52 & 0.43 & 0.42 & 0.56 \\
\hline & Significance level & 0.85 & 0.52 & 0.41 & 0.41 \\
\hline \multirow{2}{*}{ Test group } & $Z$ test & 0.68 & 0.75 & 0.35 & 0.40 \\
\hline & Significance level & 0.63 & 0.41 & 0.42 & 0.32 \\
\hline
\end{tabular}

Table 3. Levene's Test Results to Check Consistency of Error Variances in the Remembrance and Application Levels

\begin{tabular}{lcccc}
\hline Level & F Value & dfi Value & df2 Value & Significance Level \\
\hline Remembrance & 1.33 & 1 & 45 & 0.25 \\
Application & 2.01 & 1 & 45 & 0.29 \\
\hline
\end{tabular}

Table 4. The Interaction Between the Independent Variable and Pretest

\begin{tabular}{lccc}
\hline Origin & DF Value & Mean Square & Significance Level \\
\hline $\begin{array}{l}\text { The independent } \\
\text { variable and pretest }\end{array}$ & 2 & 11.65 & 0.09 \\
\hline
\end{tabular}

Table 5. ANCOVA Results Regarding Posttest Scores of Remembrance Learning Level in the Students After Adjusting for the Pretest Scores

\begin{tabular}{lccc}
\hline Changes source & $\begin{array}{c}\text { Degrees of } \\
\text { Freedom }\end{array}$ & Mean Square & $\begin{array}{c}\text { Significance } \\
\text { Level }\end{array}$ \\
\hline Intercept & 1 & 745.72 & 0.001 \\
\hline Pre-test & 1 & 0.76 & 0.09 \\
$\begin{array}{l}\text { Group } \\
\text { (Independent } \\
\text { variable) }\end{array}$ & 1 & 83.12 & 0.001 \\
\hline Error & 47 & 1.03 & \\
\hline
\end{tabular}

Table 6. ANCOVA Results Regarding Posttest Scores of Application Learning Level in the Students After Adjusting for the Pretest Scores

\begin{tabular}{lccc}
\hline Changes Source & $\begin{array}{c}\text { Degrees of } \\
\text { Freedom }\end{array}$ & Mean Square & $\begin{array}{c}\text { Significance } \\
\text { Level }\end{array}$ \\
\hline Intercept & 1 & 798.33 & 0.001 \\
\hline Pre-test & 1 & 4.01 & 371 \\
\hline $\begin{array}{l}\text { Group } \\
\text { (Independent } \\
\text { variable) }\end{array}$ & 1 & 104.20 & 0.001 \\
\hline Error & 44 & 3.85 & \\
\hline
\end{tabular}

and other resources. The results of a study conducted by Latifi (1) also indicated that the demonstrating component of Merrill's theory could improve the learning in applica- tion and remembrance levels in programing courses.

Generally, the theory of Merrill's first principles of instruction is four-stage training in which, trainer must first activate the previous experiences of learners. The activation can occur through a variety of methods such as pre-organizing, speaking, and debating about subjects, schema, and conceptual and mental maps of new knowledge in relation with previous knowledge (10). In the second stage, the instructor provides information. Providing information is not merely expressing them orally. According to the Merrill's theory of first principles of instruction, the topics must be presented by using adequate examples and the learners must be guided well. The leaning could be effective in this way. In the third stage, the application of knowledge or skill is concerned.

The teacher first helps learners apply what they have learnt and gradually reduces the extent of assistance until the learners reach a level in which they can learn the subjects independently on their own without being guided by the teacher. At the end, learners have to be able to use what they have learnt in real situations (by merging or combining). This can cause the contents provided in classroom to be a sort of applicable knowledge for the students; as a result, the extent of students learning is expanded. The effectiveness of team-based learning has been shown through various investigations. For example, Hassanzadeh et al. (11) and Jafari (17) showed that team-based learning can increase and facilitate deep learning among students. It has also increased students' participation in class activities and perhaps, due to the interactions it causes among the students, improves communication skills of medical students. One of the approaches that can make the training effective is integration of Merrill's first principles of instruction with team-based learning. 
Generally, the Merrill's theory of first principles of instruction is successful in learning due to presenting educational principles that are important and crucial for education especially when it is combined with team-based learning. The obtained results emphasized the need for applying the Merrill's first principles of instruction in combination with team-based learning in order to create active educational methods and meaningful learning. This combination showed to facilitate the achievement of educational objectives in learning in both levels of remembrance and application in various learners.

Considering the convenience sampling method used in this study, we should be cautious in generalization of the results; therefore, we recommend applying this combined method in further studies to generalize the results to other populations of learners and other academic courses. We also recommend assessing the effectiveness of Merrill's first principles of instruction by creating a tool for evaluating the quality of learning in virtual and real environments. The principles can also be examined and applied on nurses in clinical training.

\section{Acknowledgments}

This research was conducted with the cooperation of the professor of nutrition and nutritional therapy course as well as nursing students at Ardabil University of Medical Sciences, Meshkin Shahr campus; therefore, the researchers would like to appreciate all of the participants.

\section{References}

1. Latifi S. Effectiveness of instructional design models display components compared to traditional education in achieving the goals of recall and application programming course. Tehran: Faculty of Education and Psychology Allame Tabatabai University; 2013.

2. Enarson C, Cariaga-Lo L. Influence of curriculum type on student performance in the United States Medical Licensing Examination Step 1 and Step 2 exams: problem-based learning vs. lecture-based curriculum. Med Educ. 2001;35(11):1050-5. [PubMed: 11703641].

3. Shokar GS, Shokar NK, Romero CM, Bulik RJ. Self-directed learning: looking at outcomes with medical students. Fam Med. 2002;34(3):197200. [PubMed: 11922535].
4. Gardner JL. Testing the efficacy of Merrill's first principles of instruction in improving student performance in introductory biology courses. ; 2011.

5. Halpern DF, Hakel MD. Learning That Lasts a Lifetime: Teaching for Long-Term Retention and Transfer. $N$ Direct Teach Learn. 2002;2002(89):3-7. doi: 10.1002/tl.42.

6. Michael J. Where's the evidence that active learning works?. Adv Physiol Educ. 2006;30(4):159-67. doi: 10.1152/advan.00053.2006. [PubMed: 17108243].

7. Shabani H. Education, skills, techniques and teaching methods. Tehran: SAMT; 2007.

8. Saif AA. Modern educational psychology. Tehran: Doran;2011

9. Prince M. Does Active Learning Work? A Review of the Research.JEngin Educ. 2004;93(3):223-31. doi:10.1002/j.2168-9830.2004.tb00809.x.

10. Badali M. Asses the instructional design based impact Merrill's first principles of instruction on the student's extent of learning and retention in biology. Tehran: Allameh Tabatabai University; 2013.

11. Hassanzadeh G, Abolhasani F, Mirzazadeh A, Alizadeh M. Team-Based Learning A New Strategy in Integrated Medical Curriculum: The experience of School of Medicine, Tehran University of Medical Sciences. Iran J Med Educ. 2013;13(7):601-10.

12. Parmelee DX. Team-based Learning for health professions education: Why is it a good put?. In: Michaelsen L, Parmelee DX, McMahon KK, Levine RE, editors. Team-based learning for health professions education. Sterling, Virginia: Stylus Publishing; 2008. p. 1.

13. Merrill MD. First principles of instruction. Educ Technol Res Dev. 2002;50(3):43-59. doi: 10.1007/bf02505024.

14. Norozi D, Dehghanzadeh H. Designing educational computer games. Tehran: Goyeshe Noo; 2011.

15. Ding R, Frei E, Fardanesh M, Schrenk HH, Kremer P, Haefeli WE. Pharmacokinetics of 5-aminofluorescein-albumin, a novel fluorescence marker of brain tumors during surgery. J Clin Pharmacol. 2011;51(5):672-8. doi: 10.1177/0091270010372626. [PubMed: 20978277].

16. Archibald TN. The effect of the integration of social annotation technology, first principles of instruction, and team-based learning on students' reading comprehension, critical thinking, and metacognitive skills. Department of Educational Psychology and Learning Systems; 2010

17. Jafari Z. Comparison of rehabilitation students' learning in neurology through lecture with team-based learning (TBL). Iran J Med Educ. 2013;13(6):448-56.

18. Zare'I Zavaraki E, Badali M, Amirteimuri M. Assess the impact Merrill's first principles of instruction on the students' extent of learning and retention. J $N$ thoughts Educ Univ Al Zahra. 2013;9(4):55-73.

19. Thompson_Ins . Thompson job impact study. Naperville Il: Thompson NETg; 2002.

20. Nordhoff HI. The design and implementation of a computer-based course using Merrill's model of instructional design. ; 2003.

21. Merrill MD. First principles of instruction. San Francisco: Pfeiffer; 2009. 